\title{
Scrolling for data or doom during COVID-19?
}

\author{
Paige Paulsen $^{1}$ (D) Daniel Fuller ${ }^{1}$
}

Received: 11 June 2020 / Accepted: 23 June 2020 / Published online: 8 July 2020

(C) The Canadian Public Health Association 2020

\section{Dear Editor:}

The eerie sight of empty playgrounds, grocery shelves, and schools serves as a constant reminder of the newfound presence in our daily lives - COVID-19. Scrolling through social media platforms has the same effect. An endless sequence of posts that pertain to the novel coronavirus clutters our threads. Even with attempts to moderate use or filter content, the looming presence of COVID-19 remains. Although social media can be mentally taxing at times, it has and continues to be an invaluable resource to share information and provide evidence-based content online. However, attempting to maintain relevance for the Canadian Journal of Public Health (CJPH) during these times has proven difficult.

COVID-19 has influenced our use of technology. Not only have we been forced online to complete the majority of our work, but physical distancing means our social lives have moved online to find shared interactions. Many organizations have capitalized on this online presence by amending their promotional material to incorporate COVID-19 or related content. We steered CJPH accounts in the same direction.

Having recently assumed the role of assistant to the Social Media Associate Editor, it has been encouraging to see the impact of a committed social media presence. However, COVID-19 disrupted our standard line-up of posts, marked by a dwindling number of impressions and engagements. The CJPH social media aims to engage our followers to act as a hub of relevant information (Fuller and Potvin 2020). During this time, it was apparent that we could either adapt to fulfill the appetite for COVID-19 material or post material that seemed

Paige Paulsen

ppaulsen@mun.ca

Daniel Fuller

dfuller@mun.ca

1 Memorial University of Newfoundland, St. John's, NL, Canada irrelevant. We decided to harness the new potential of our social media platforms by leaning into the pandemic.

Prior to COVID-19, there was an emphasis on promoting Online First articles. These posts were replaced by two separate categories: featured COVID-19 researcher of the week and past CJPH publications with an infectious disease theme. Researchers of the week were selected from the list of Government of Canada-funded COVID-19 projects. Posts highlighted their contributions and past CJPH publications. Similarly, we retrieved past publications that contained pandemic or infectious disease content to provide a relevant distraction. CJPH recently revealed a special section on COVID-19, therefore creating a home for COVID-19-related contributions.

Pandemics seem to have a specific signature; a lasting characteristic that is separate from the devastation of the associated morbidity and mortality. Through the course of the current pandemic, information coupled with misinformation, rumours, and conspiracy theories were rapidly disseminated through social media. For example, statements that individuals can be protected or cured from COVID-19 by consuming alcohol, hydroxychloroquine, or adding hot peppers to meals (WHO n.d.). Addressing the additional pandemic of social media panic has accompanied the utilization of public health measures to control the transmission of the novel coronavirus (Depoux et al. 2020).

Distinguishing between accurate and inaccurate information spread through social media can be difficult. This spread of misleading propaganda leads to fear, anxiety, and confusion (Rosenberg et al. 2020). Luckily, there are many benefits to these platforms. Social media can be harnessed and utilized as a tool to communicate public health measures. The task of providing the public with daily updates on active cases, prevention strategies, and restrictions aims to increase awareness of the general population (Gao et al. 2020). Social media also facilitates exchanges in the public health community by enabling further communication and connection (Fuller and Potvin 2020). Together, this public health community can help promote accurate information 
and fight misinformation locally, nationally, and internationally (Rosenberg et al. 2020).

COVID-19 has brought hardship and new challenges for many. Throughout the uncertainty that comes with encountering a novel disease, the work of public health has been more important than ever. COVID-19 has pulled public health into the public eye, requiring committed leadership, guidance, and research. The recent spotlight brings new expectations along with never-ending workdays. The public health community has embraced the task at hand while enduring the same concerns about the health of their family and friends. For those of us trying to continue to promote the exceptional work of this public health community, we are required to remain flexible in order to provide followers with reliable and relevant material. COVID-19 will remain in our presence for the unforeseeable future; we must continue to remain connected, engaged, and informed.

\section{References}

Depoux, A., Martin, S., Karafillakis, E., Preet, R., Wilder-Smith, A., \& Larson, H. (2020). The pandemic of social media panic travels faster than the COVID-19 outbreak. Journal of Travel Medicine, 27(3), 1-2.

Fuller, D., \& Potvin, L. (2020). Social media and the Canadian Journal of Public Health. Canadian Journal of Public Health, 111, 149-150.

Gao, J., Zheng, P., Jia, Y., Chen, H., Mao, Y., Chen, S., Wang, Y., \& Dai, J. (2020). Mental health problems and social media exposure during COVID-19 outbreak. PLoS One, 15(4), e0231924.

Rosenberg, H., Syed, S., Rezaie, S. (2020). The twitter pandemic: The critical role of twitter in the dissemination of medical information and misinformation during the COVID-19 pandemic. CJEM. 104.

World Health Organization [WHO].n.d. Coronavirus disease (COVID19) advice for the public: Myth busters. Retrieved from: https:// www.who.int/emergencies/diseases/novel-coronavirus-2019/ advice-for-public/myth-busters

Publisher's note Springer Nature remains neutral with regard to jurisdictional claims in published maps and institutional affiliations. 